\title{
Identification and characterization of genes encoding sex pheromone cAM373 activity in Enterococcus faecalis and Staphylococcus aureus
}

\author{
Susan E. Flannagan ${ }^{1}$ and Don B. Clewell ${ }^{1,2 *}$ \\ ${ }^{1}$ Department of Biologic and Materials Sciences, School \\ of Dentistry, The University of Michigan, $1011 \mathrm{~N}$. \\ University Ave., Ann Arbor, MI 48109-1078, USA. \\ ${ }^{2}$ Department of Microbiology and Immunology, School \\ of Medicine, The University of Michigan, Ann Arbor, \\ MI 48109, USA.
}

\section{Summary}

The sex pheromone cAM373 of Enterococcus faecalis and the related staph-cAM373 of Staphylococcus aureus were found to correspond to heptapeptides located within the C-termini of the signal sequences of putative prelipoproteins. The deduced mature forms of the lipoproteins share no detectable homology and presumably serve unrelated functions in the cells. The chromosomally encoded genetic determinants for production of the pheromones have been identified and designated camE (encoding cAM373) and cams (encoding staph-cAM373). Truncated and full-length clones of camE were generated in Escherichia coli, in which cAM373 activity was expressed. In E. faecalis, insertional inactivation in the middle of camE had no detectable phenotypic effects on the pheromone system. Establishment of an in frame translation stop codon within the signal sequence resulted in reduction of CAM373 activity to $3 \%$ of normal levels. The cams determinant has homologues in Staphylococcus epidermidis, Bacillus subtilis and Listeria monocytogenes; however, corresponding heptapeptides present within those sequences do not resemble staph-cAM373 closely. The particular significance of staph-cAM373 as a potential intergeneric inducer of transfer-proficient genetic elements is discussed.

\section{Introduction}

The observation that Enterococcus faecalis strains containing certain plasmids give rise to bacterial aggregates

Accepted 31 January, 2002. *For correspondence at the Department of Biologic and Materials Sciences. E-mail dclewell@umich.edu; Tel. (+1) 734763 0117; Fax (+1) 7347639905.

(C) 2002 Blackwell Science Ltd when mixed with plasmid-free cells led to the discovery of bacterial sex pheromones (Dunny et al., 1978). These small, hydrophobic, linear peptide molecules act as signals that facilitate the conjugative transfer of a specific category of plasmids referred to as pheromoneresponsive plasmids (for reviews on this subject, see Clewell, 1993; 1999; Wirth, 1994; Dunny and Leonard, 1997). Pheromones secreted by plasmid-free cells can, upon detection, induce a process in which plasmidcontaining cells become activated for both adherence to potential recipients (those that produced and secreted the pheromone) and plasmid transfer. Donor cells exposed to culture supernatants of potential recipients respond by undergoing a clumping response that serves as the basis of a convenient assay for pheromone activity (Dunny et al., 1979). Indeed, donor-donor transfer actually occurs under these conditions (Clewell and Brown, 1980; De Boever and Clewell, 2001).

Once a recipient cell acquires a given plasmid, the corresponding pheromone is no longer detected in the culture supernatant of the transconjugant because of 'shutdown' or 'masking' of the endogenous peptide, although pheromones specific for unrelated plasmids continue to be secreted. The newly resident plasmid encodes and directs the production of a small peptide that is somewhat similar to its cognate pheromone but acts as a competitive inhibitor. This serves to prevent plasmid induction caused by residual amounts of endogenous pheromone, thus ensuring that induction takes place only in the presence of pheromone concentrations sufficient to indicate that successful transfer to potential recipients is likely to occur.

Pheromone-responding plasmids are highly transmissible between strains of $E$. faecalis and are believed to contribute to the horizontal dissemination of antibiotic resistance genes (Clewell, 1990) and virulence factors such as cytolysin (Gilmore et al., 1994) and adhesins (Hirt et al., 2000; Rozdzinski et al., 2001); the occurrence of such virulence determinants in enterococci used as food and dairy starter cultures has raised some concern (Eaton and Gasson, 2001). Among medical isolates, the fact that vancomycin resistance is prevalent (Arthur and Courvalin, 1993; Clark et al., 1993), often combined with multiple antibiotic resistances (Murray, 1998), is of significant clinical consequence. As opportunistic pathogens of growing 
concern, particularly with regard to nosocomial infections involving urinary tract or wound infections, bacteraemia and endocarditis (Huycke et al., 1998), enterococci are also likely to serve as a potential reservoir of genes available to other Gram-positive bacteria (Clewell, 1981).

The E. faecalis pheromone-responsive plasmid pAM373, which has recently been sequenced in its entirety (De Boever et al., 2000), has the unusual ability to respond not only to a specific $E$. faecalis peptide, cAM373, but also to peptides with similar activities secreted by the non-enterococcal species Streptococcus gordonii and Staphylococcus aureus (Clewell et al., 1985). These activities were initially identified by their ability to induce a clumping response in E. faecalis cells harbouring pAM373. The staphylococcal peptide has been identified (Nakayama et al., 1996) and differs from the enterococcal peptide by only one amino acid - an alanine rather than a serine at the carboxyl-terminus. Although it is not known whether the peptides produced by different genera actually represent sex pheromones significant to these organisms, it is conceivable that they could play a role in the acquisition of pAM373 and related plasmids from enterococci. This interesting relationship, between an $E$. faecalis conjugative plasmid and peptides secreted by diverse species including the pathogen $S$. aureus, prompted an effort to identify the genetic basis for the production of the related pheromone activities.

A

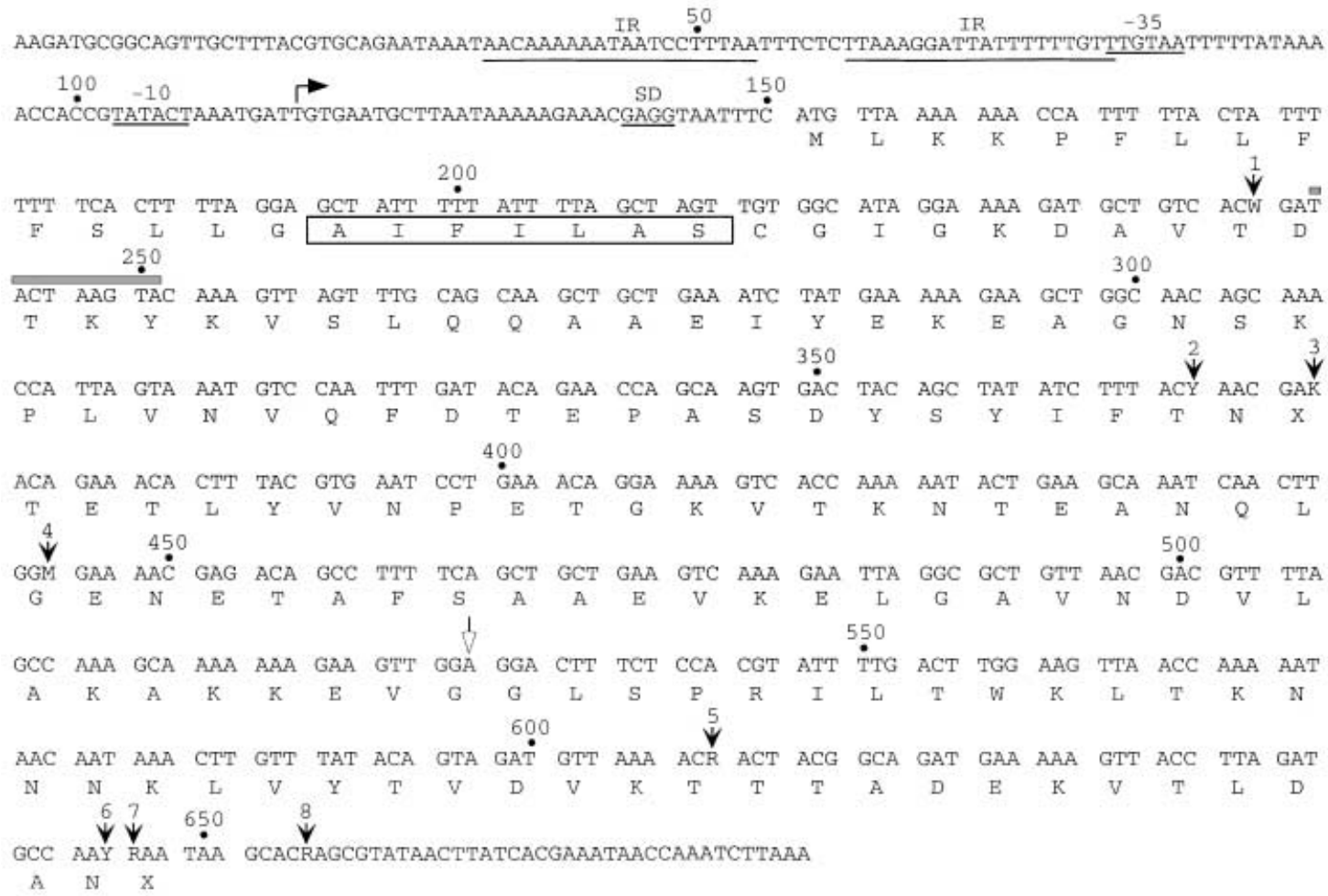

B

Variation in nucleotide bases among strains

\begin{tabular}{c|cccccccc}
\hline Strain & \multicolumn{3}{|c}{ Position } & & & & & \\
\cline { 2 - 8 } & 1 & 2 & 3 & 4 & 5 & 6 & 7 & 8 \\
\hline JH2-2 & A & C & G & C & A & T & A & G \\
OG1X & T & T & T & C & A & C & A & A \\
DS16 & T & T & T & A & A & C & G & A \\
RC73 & T & T & T & A & A & C & G & A \\
V583 & A & T & T & C & G & T & A & A
\end{tabular}

Fig. 1. The nucleotide sequence of $c a m E$ and comparison among strains. A. Single-letter amino acid designations are shown below the codons of the open reading frame $(X$ represents a position that differs depending on the strain). Shine-Dalgarno (SD), inverted repeat (IR) and promoter elements $(-35$ and -10$)$ are underlined. The transcription start site is indicated by a rightward-pointing arrow. The cAM373 heptapeptide moiety is boxed. Positions that exhibit strain differences in nucleotide base are indicated by solid arrows ( $\mathrm{K}=\mathrm{G}$ or $\mathrm{T}, \mathrm{M}=\mathrm{A}$ or $\mathrm{C}, \mathrm{R}=\mathrm{A}$ or $\mathrm{G}, \mathrm{W}=\mathrm{A}$ or $\mathrm{T}$, $\mathrm{Y}=\mathrm{C}$ or $\mathrm{T}$ ). The site of mutation (adenine to cytosine) in pAM414 is marked by an open arrow. The nucleotides corresponding to a hot-spot for IS10 integration (Halling and Kleckner, 1982) are indicated by a thick shaded line.

B. The numbered positions correspond to those shown by solid arrows in (A). Nucleotide variation results in amino acid variation at only two sites: glutamic acid when guanine is at position 3 or aspartic acid when thymine is at position 3 , and lysine when adenine is at position 7 or glutamic acid when guanine is at position 7 . 
Since the initial observations of sex pheromoneinduced bacterial clumping, unsuccessful attempts have been made to identify the chromosomally encoded genetic determinants for pheromone production; however, the abundance of genomic sequence data that have recently become available has enabled detection of these long sought after genes (Clewell et al., 2000). The present study focuses on a characterization of the determinant (camE) of cAM373 in E. faecalis as well as the identification of the staph-cAM373 determinant (camS) in S. aureus.

\section{Results}

The camE gene of $\mathrm{E}$. faecalis

The nucleotide sequence of the determinant for the precursor of CAM373 in E. faecalis, designated camE (for cAM373 of E. faecalis), is presented in Fig. 1. A 498 nucleotide (nt) open reading frame (ORF) is preceded by a potential ribosome binding site (RBS) as well as -10 and -35 promoter elements. The sequences from five non-isogenic $E$. faecalis strains are compared. JH2-2 and OG1X are commonly used laboratory strains, whereas DS16 and V583 are clinical isolates resistant to multiple antibiotics. RC73 is the original source of the pheromoneresponsive plasmid $\mathrm{PAM} 373$. It is of interest to note that complete sequence information for the region presented in Fig. $1 \mathrm{~A}$ is now available in the database of The Institute for Genomic Research (TIGR) for strain V583, which matches exactly the sequence for V583 determined here. There are seven positions within the ORF at which nucleotide variation occurs. All but one involve the third nucleotide of a codon, and nucleotide changes at only two positions result in amino acid changes (Fig. 1B).

The ORF shown in Fig. 1A can be extended upstream to an in frame start codon, which would add 10 amino acids to the deduced peptide; however, because a related RBS is not apparent, it is unlikely that translation could begin at this site. Primer extension analyses of RNA transcripts from strain $\mathrm{JH} 2-2$ placed the start of transcription for camE $8 \mathrm{nt}$ away from the proposed -10 promoter sequence (see Fig. 2).

The camE gene specifies a putative prelipoprotein of $18.2 \mathrm{kDa}$ (166 amino acids) including a typical hydrophobic signal sequence (Fig. 3A). A cysteine residue after the signal sequence cleavage site, as well as the presence of a leucine residue at the -3 position ( $L-x-x-$ cleavage-C), is typical for lipoprotein signals of both $E$. coli $(\mathrm{Wu}, 1996)$ and Bacillus (Nagarajan, 1993). The pheromone cAM373 (AIFILAS) corresponds to the last seven amino acids of the carboxyl-terminal end of the signal sequence. Database searches revealed no significant homologies between the lipoprotein and other known proteins.

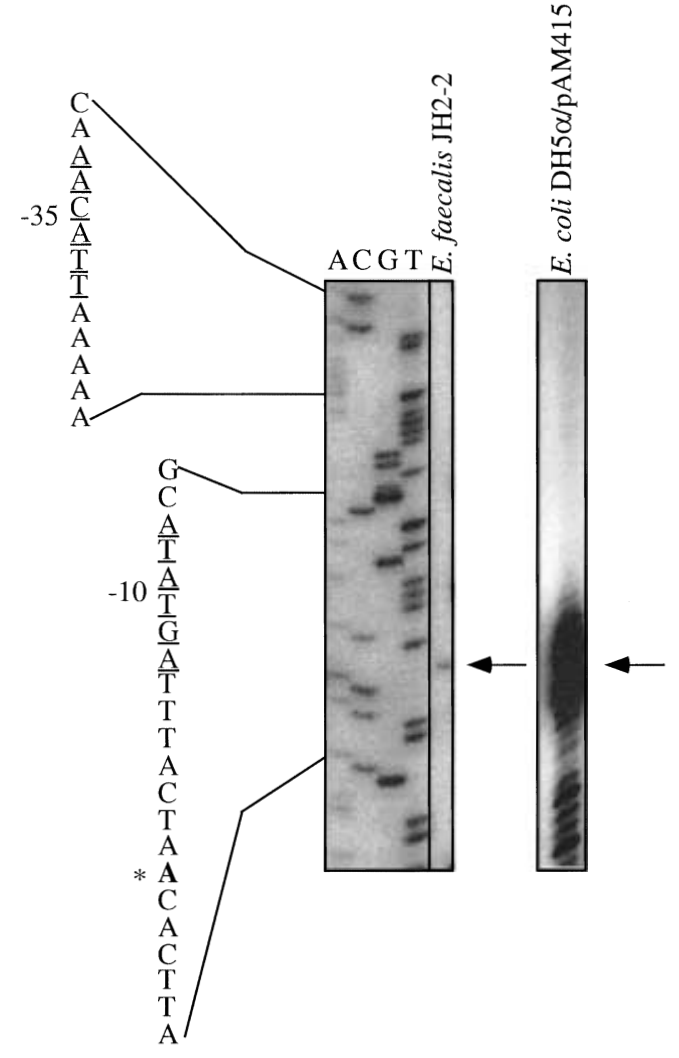

Fig. 2. Transcription start site of camE. DNA sequencing of template pAM415 is shown in the lanes marked A, C, G and T. Primer extensions using total cellular RNA templates are shown in the lanes labelled with the appropriate strain name. Primer EF3738 was used. The promoter elements $(-35$ and -10$)$ are underlined. The arrows indicate the primer extension products. The adenine residue marked with an asterisk represents the $3^{\prime}$ end of the primer extension product and corresponds to the thymine residue illustrated as the transcription start site in Fig. 1. Although the exact start site is unclear in the case of the high-copy E. coli plasmid, the alignment of the major product with that of $E$. faecalis, combined with the lack of higher bands, indicates that the camE promoter is driving transcription in E. coli.

\section{Neighbouring determinants of camE}

By compiling information from the TIGR database, the local organization of the chromosome could be viewed in the region of the camE gene in E. faecalis V583 (Fig. 4A). The camE gene is just upstream of an ORF of $459 \mathrm{bp}$. The location suggests that the two genes may be transcribed as a unit, and a potential transcription terminator appears immediately downstream, whereas no terminator is evident directly after camE. Situated upstream of camE are components that probably form an ATP-binding cassette $(A B C)$ transporter.

\section{Cloning of camE in $\mathrm{E}$. coli}

The full-length camE gene, including the promoter region preceded by an apparent intrinsic transcription terminator, 

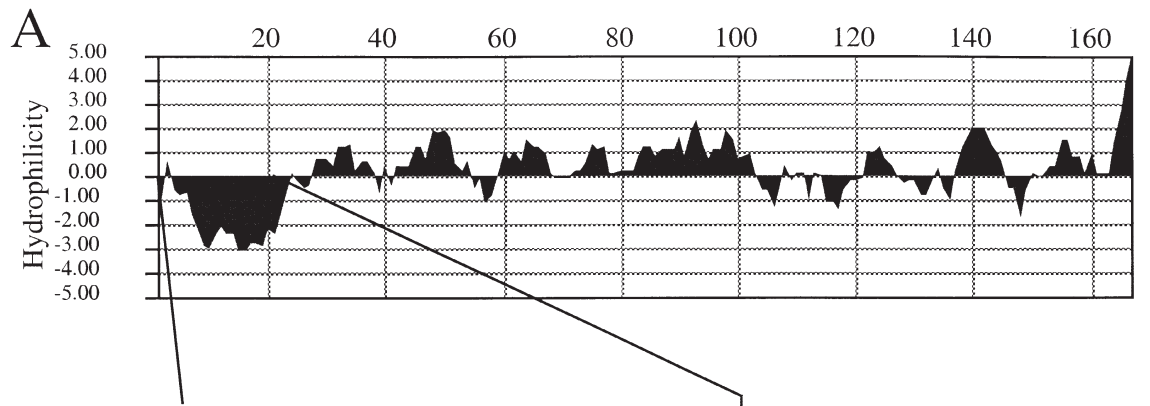

\section{CamE}

Size $=166$ amino acids

Molecular Weight $=18.2 \mathrm{kDa}$

Estimated $\mathrm{pI}=5.14$

MLKKPFLLFFSLLGAIFILASCGI... CamE signal sequence of E. faecalis JH2-2 cAM373

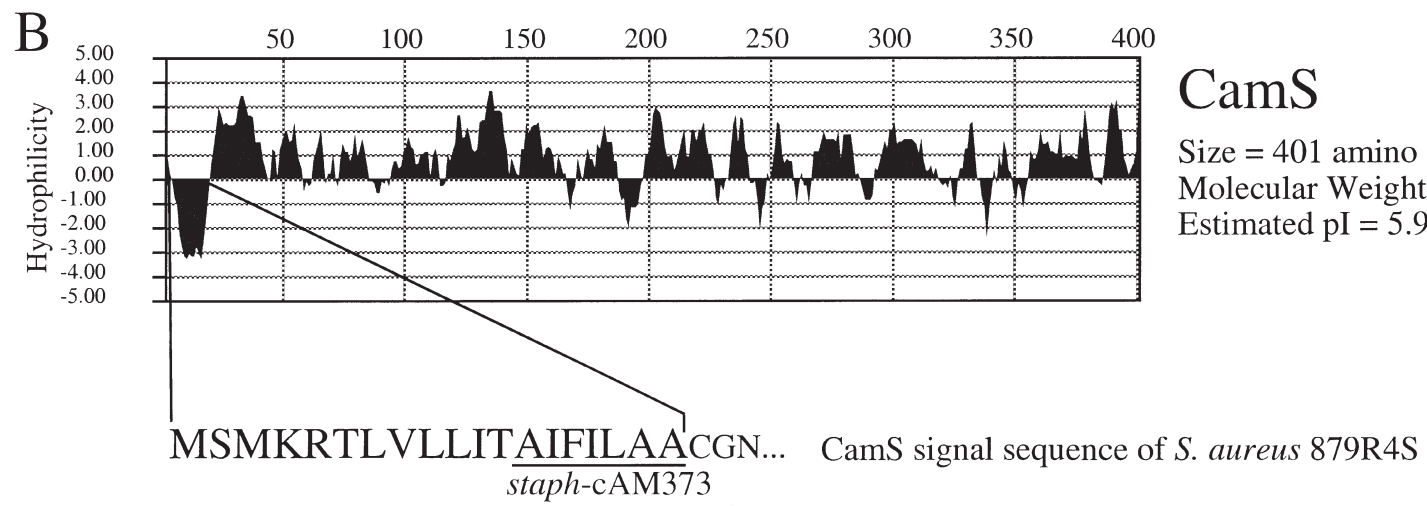

Fig. 3. Physical characterization of CamE of E. faecalis JH2-2 and CamS of S. aureus 879R4S. Hydophilicity of each protein is plotted. The amino acid sequence of the hydrophobic signal sequence is shown below.

A. The heptapeptide corresponding to pheromone cAM373, derived from the end of the CamE signal sequence, is underlined.

B. The heptapeptide corresponding to pheromone staph-cAM373, derived from the end of the CamS signal sequence, is underlined.

was amplified as a $0.9 \mathrm{~kb}$ fragment from $E$. faecalis $\mathrm{JH} 2-$ 2 and cloned into pUC19 at the unique EcoRI site. Surprisingly, ampicillin-resistant transformants were obtained in very low numbers, and no clones were found with a camE nucleotide sequence completely identical to wild type. One isolate, pAM414, has only a single point mutation (Fig. 1A) that does not alter the deduced product; the transformant expressed CAM373 activity that could be detected in culture supernatants at a titre of 16 . The low efficiency of transformation suggests that expression of CamE may be detrimental to the E. coli host, with the pAM414 derivative representing selection of a 'tolerant' host variant. Consistent with this was the observation that several transformants had an IS10-R sequence (apparently host derived) inserted in an IS10 hot-spot located within camE (Fig. 1A).

An artificially truncated segment of camE was cloned more readily, creating PAM415. By inclusion in the primer design, the cysteine codon (TGT) immediately after the pheromone-coding region was changed to a stop codon (TGA), thereby eliminating the need for processing at the carboxyl-terminal end of the heptapeptide. Orientation of the insert is counter to the direction of transcription of $\beta$ - galactosidase through the cloning site of the vector and, in addition, an apparent intrinsic transcription terminator that occurs naturally just upstream of the camE promoter is included, which should prevent readthrough of any vector-initiated transcripts. Primer extension analysis indicates that transcription of camE in the E. coliclone is driven by the natural promoter (Fig. 2). A high level of CAM373 activity (titre $=2048$ ) was expressed from this isolate, indicating that production and export of cAM373 activity is not detrimental to $E$. coli.

\section{Mutation of camE}

Single cross-over mutants of camE in E. faecalis $\mathrm{JH} 2-2$ were generated by homologous recombination of the chromosome with cloned fragments internal to camE located on the suicide plasmid pAM434, as described in Experimental procedures. Neither of the two separately cloned segments involved the signal sequence encoded by camE. The plasmids pAM434-380 and pAM434-250, which are unable to replicate in $E$. faecalis, were introduced into $\mathrm{JH} 2-2$ by electroporation, producing strains SF380 and SF250 respectively. Integration generated an 


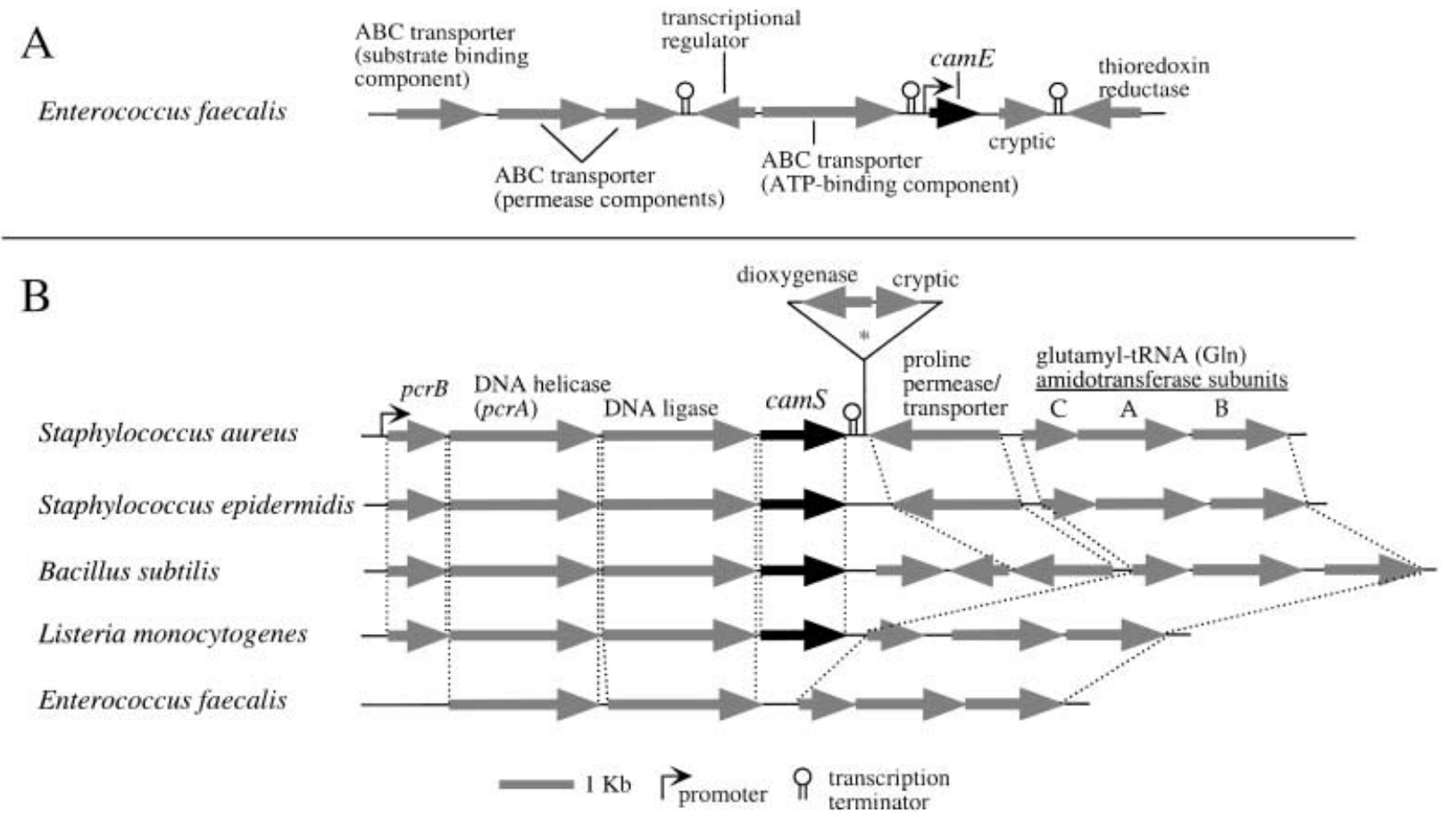

Fig. 4. Genetic determinants in the area of $\operatorname{camE}(\mathrm{A})$ or camS (B). Functional designations are based on homology comparisons, at the protein level, with entries in the GenBank database. Gene homologues among the genera are grouped by dotted lines. Only selected transcription promoters and terminators are illustrated. Data for $S$. aureus strain COL is from the TIGR database, with an additional segment illustrated (marked by an asterisk) for strain 879R4S (this study); E. faecalis strain V583 data are compiled from this study and from the TIGR database; data for S. epidermidis strain RP62A and L. monocytogenes strain 4-b are from the TIGR database; data for B. subtilis strain 168 are compiled from Petit et al. (1998) and from the SubtiList website (http://genolist.pasteur.fr/SubtiList/).

expected partial duplication of camE, with the partial gene copies interrupted by the vector as shown by Southern blot hybridization (Fig. 5), and resulted in gene disruption affecting $8 \%$ or $25 \%$ of the $3^{\prime}$ end of camE for isolates SF380 and SF250 respectively. The greater disruption was expected to result in certain elimination of a functional gene product, whereas the lesser disruption was designed specifically to test the importance of the $3^{\prime}$ terminal portion of the gene. Restoration of genomic DNA to the wild-type pattern was seen in the case of representative revertants (Fig. 5).

The plasmid-free camE mutants and revertants were found to produce normal amounts of cAM373 (Table 1), as would be expected as one of the partially duplicated gene segments should have a normal $5^{\prime}$ end. The other known pheromone peptides, CAD1, CCF10, CPD1 and COB1, were produced at normal levels as well, as shown by mutant SF250 (Table 2). Upon introduction of pAM378 (pAM373 carrying a tetracycline resistance marker), the cAM373 pheromone activity was, like the wild-type JH22, undetectable for the mutant and revertant strains (Table 1). Each plasmid-containing strain exhibited a typical clumping response to synthetic pheromone and exhibited a normal donor potential, implying that the camE lipoprotein is not critical for normal plasmid trans-

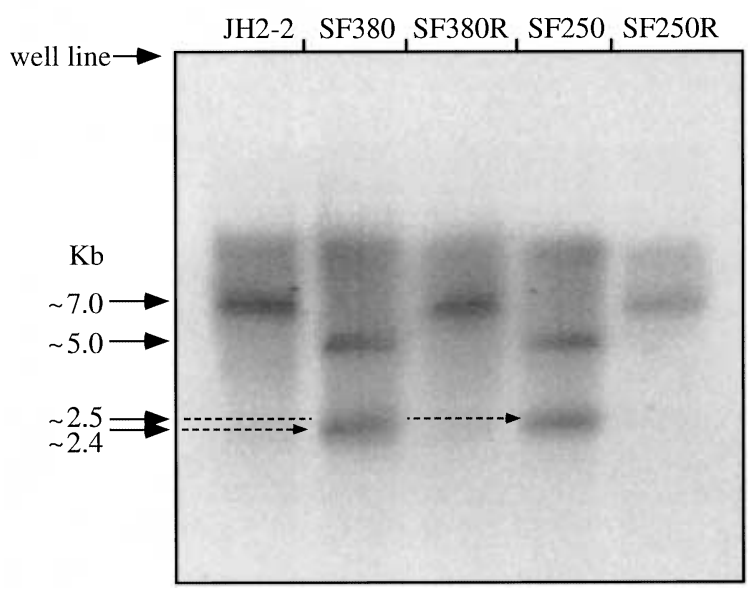

Fig. 5. Southern blot hybridization showing integration of the suicide vector pAM434 into camE of JH2-2 and subsequent reversion to wild type. Genomic DNA from each strain (as labelled) was digested with $E c o R I$ and probed with a $398 \mathrm{bp} \mathrm{PCR} \mathrm{product}$ internal to camE (made using primers Ef373-2 and Ef373-3). Fragment sizes were estimated by comparison of a phosphorescent ruler image on the autoradiograph with a fluorescent ruler image on the photograph of the gel, which included a molecular weight marker ladder. Strain SF380 contains $\approx 0.4 \mathrm{~kb}$ more hybridizing DNA than the wild type because of incorporation of the $380 \mathrm{bp}$ homologous fragment on pAM434-380. Strain SF250 contains about $0.5 \mathrm{~kb}$ more than the wild type because two tandem copies of the $250 \mathrm{bp}$ homologous fragment are present on PAM434-250. 
Table 1. Phenotype of the camE mutants and revertants ${ }^{\mathrm{a}}$.

\begin{tabular}{|c|c|c|c|c|c|c|}
\hline \multirow[b]{2}{*}{ Strain } & \multirow[b]{2}{*}{ 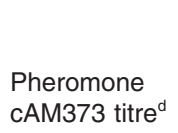 } & \multirow[b]{2}{*}{$\begin{array}{l}\text { Response to } \\
\text { pheromone }^{\text {ce }}\end{array}$} & \multirow[b]{2}{*}{$\begin{array}{l}\text { Inhibitor } \\
\text { iAM373 titre }\end{array}$} & \multicolumn{3}{|c|}{ Transfer frequency ${ }^{b c}$} \\
\hline & & & & As recipient & $\begin{array}{l}\text { As recipient } \\
\text { (+ pheromone) }\end{array}$ & As donor \\
\hline JH2-2 (wild type) & $64-128$ & NA & NA & $4.2 \times 10^{-2}$ & $8.8 \times 10^{-2}$ & NA \\
\hline SF380 & $64-128$ & NA & NA & ND & ND & NA \\
\hline SF380R & $64-128$ & NA & NA & ND & ND & NA \\
\hline SF250 & $64-128$ & NA & NA & $5.6 \times 10^{-2}$ & ND & NA \\
\hline SF250R & $64-128$ & NA & NA & ND & ND & NA \\
\hline SF13R & $2-4$ & NA & NA & $6.3 \times 10^{-3}$ & $1.4 \times 10^{-1}$ & NA \\
\hline JH2-2/pAM378 & $<2$ & $6.3,12.5$ & 16 & NA & NA & $3.4 \times 10^{-2}$ \\
\hline SF380/pAM378 & $<2$ & $6.3,12.5$ & 16 & NA & NA & ND \\
\hline SF380R/pAM378 & $<2$ & $6.3,12.5$ & 16 & NA & NA & ND \\
\hline SF250/pAM378 & $<2$ & $6.3,12.5$ & 16 & NA & NA & $5.0 \times 10^{-2}$ \\
\hline SF250R/pAM378 & $<2$ & $6.3,12.5$ & 16 & NA & NA & ND \\
\hline SF13R/pAM378 & $<2$ & $6.3,12.5$ & 16 & NA & NA & $2.8 \times 10^{-2}$ \\
\hline
\end{tabular}

a. All results are based on three independent tests. In some cases, a range of values is given; when one value is given, it represents the mean b. Transfer frequency (transconjugants/donor) in a $4 \mathrm{~h}$ broth mating involving JH2SS or JH2SS/pAM378. Pheromone, when added, was synthetic cAM373 (50 $\left.\mathrm{ng} \mathrm{m}^{-1}\right)$.

c. NA, not applicable; ND, not determined.

d. The pheromone titre is the reciprocal of the highest dilution of culture supernatant producing clumping of responder FA373.

e. The response to pheromone is measured as the lowest concentration $\left(\mathrm{ng} \mathrm{ml}^{-1}\right)$ of synthetic pheromone for which clumping is observed. The concentration of cAM373 is listed first, followed by the concentration of staph-cAM373. Note that pAM378 is not as sensitive to pheromone as pAM373.

f. The inhibitor titre is calculated by testing clumping of a responder to synthetic pheromone. The clumping titre in the absence of test supernatant divided by the clumping titre in the presence of supernatant is the inhibitor titre. The results were the same using synthetic cAM373 or synthetic staph-cAM373.

fer. The cells also secrete normal levels of the inhibitor peptide iAM373 (Nakayama et al., 1995).

\section{Mutation that includes the camE signal sequence}

Isolate SF13R was generated (as described in Experimental procedures) with a translation stop codon resulting from a frameshift in the region of camE encoding the signal sequence, but lacking any other alteration in the camE gene. Despite the presence of the stop codon immediately upstream of the pheromone-coding region, low-level (3\% of normal) CAM373 activity was observed, whereas production of other pheromones was normal (Table 2). The low-level clumping-inducing activity is probably produced from a different location (possibly involving derivatives from signal sequences of other lipoprotein precursors), rather than residual activity from the camE gene unless significant translational 'slippage' takes place in the multiadenine region in which the deletion occurred, thereby re-establishing the correct reading frame. Data from Fig. 5 and additional hybridizations of a genespecific probe with total genomic DNA digested with a variety of restriction enzymes (data not shown) rule out the possibility of more than one copy of camE. There exists a potential RBS (AGGAG) partially overlapping and extending beyond the stop site. If translation begins again at this location, it is possible that a shorter form of CAM373 could be produced starting with codon ATT that can be used in some cases (Singleton and Sainsbury, 1996). The short form would be a hexapeptide (MFILAS) and not likely to be exported, as it would not be part of a signal sequence. In addition, the hexapeptide was produced synthetically and shown to lack clumping-inducing activity (up to a concentration of $500 \mathrm{ng} \mathrm{ml}^{-1}$ ).

Table 2. Pheromone titres of culture supernatants ${ }^{\mathrm{a}}$.

\begin{tabular}{lllrr}
\hline & Pheromone-responsive & & \\
Responder strain & plasmid in responder strain & JH2-2 titre & SF250 titre & SF13R titre \\
\hline OG1X/pAM373 & pAM373 & 128 & 128 & 4 \\
OG1X/pAD1 & pAD1 & 128 & 128 & 128 \\
OG1SS/pCF10 & pCF10 & 16 & 16 & 16 \\
$39-5$ & pPD1 & 16 & 16 & 0.8 \\
$5952^{\text {b }}$ & pOB1 & 0.8 & 0.8 \\
\hline
\end{tabular}

a. The pheromone titre is the reciprocal of the highest dilution of culture supernatant inducing clumping of the responder strain.

b. Concentration $(5 x)$ of each test supernatant was necessary in order to observe clumping of 5952 . 
In an attempt to identify additional prelipoprotein genes encoding peptides with similarity to cAM373, a computer search was performed of the $E$. faecalis V583 genome in the TIGR database. The closest match found specifies a heptapeptide sequence of AIFALGA (matching cAM373 at four positions). This synthetic peptide was found to induce clumping of FA373 only at extremely high levels (a minimum of $500 \mathrm{ng} \mathrm{ml}^{-1}$ ), which are considered unlikely to be produced in vivo.

The wild-type JH2-2 strain and the mutant SF13R did not serve equally well as plasmid recipients, with transconjugant frequency lowered by about one order of magnitude in the case of the mutant (Table 1). However, when mating mixtures were supplied with synthetic pheromone, both the wild-type and the mutant strains supported comparably high transfer frequencies, indicating that the mutant's lowered recipient ability reflects poor mating as a result of less pheromone production, not from inhibition of plasmid entry or establishment. In this regard, it is noted that the entire lipoprotein moiety of CamE should be absent in the mutant. Introduction of pAM378 into the mutant strain resulted in cells that exhibited normal clumping and donor potential, and the production of iAM373 was similar for both SF13R and the wild-type host (Table 1).

\section{The camS gene of S. aureus}

Preliminary information from genome databases led to the identification of a $1.2 \mathrm{~kb}$ ORF in $S$. aureus strain 879R4S encoding an apparent lipoprotein precursor with a signal sequence containing staph-cAM373 (AIFILAA), the staphylococcal version of cAM373, immediately adjacent to a lipoprotein signal peptidase processing site (Fig. 3). A potential RBS was found to precede two closely spaced start codons. For the purpose of gene product description, the first start codon is presumed to be functional. The ORF was designated camS (for $\underline{\mathrm{cAM}} 373$ of $\underline{S}$. aureus) and is $1203 \mathrm{bp}$ long (data available in GenBank under accession number AF435443). Sequence information is available in the TIGR database for a similar gene from $S$. aureus COL. Comparison of the two DNA sequences showed nucleotide differences at 10 positions within the ORF, with concomitant amino acid changes at two sites (proline to serine at amino acid position 208, and isoleucine to valine at amino acid position 329). These may represent true genetic variations between strains; however, it is noted that the TIGR data are, at present, classified as part of an unfinished genome and may be subject to change.

The mature forms of CamE and Cams share no detectable homology except in the heptapeptide pheromone regions. CamS exhibits homology (32\% iden- tity) with the cryptic YerH of Bacillus subtilis (Petit et al., 1998).

\section{The camS locale and comparison of cams homologues}

Information from the TIGR database was used to view the local organization of the chromosome in the region of the cams-like gene in S. aureus strain COL (Fig. 4). Direct sequencing of the region around cams in $S$. aureus $879 \mathrm{R} 4 \mathrm{~S}$ revealed the presence of $1.8 \mathrm{~kb}$ of DNA downstream of cams that is absent in strain COL (the $1.8 \mathrm{~kb}$ segment of $879 \mathrm{R} 4 \mathrm{~S}$ is found in place of a $10 \mathrm{bp}$ segment of COL). Two major ORFs found in this 'additional' segment of 879R4S showed homologies with proteins in the GenBank database: one with dioxygenase and the other with a conserved but uncharacterized hypothetical protein. No inverted or direct repeats were found flanking this segment, indicating that it is probably not a mobile DNA element. Genes for proline permease are found in both strains; however, the inverted repeat apparently serving as a bidirectional transcription terminator for the opposing genes in COL, and associated with the proline permease genes of other $S$. aureus strains (Wengender and Miller, 1995; Schwan et al., 1998), is only found adjacent to the cams gene in strain 879R4S, indicating that $879 \mathrm{R} 4 \mathrm{~S}$ may be somewhat unique in this regard. The organization of genes of the $S$. aureus chromosome including cams and upstream regions bears striking similarity to that of Staphylococcus epidermidis, Bacillus subtilis and Listeria monocytogenes. The camS gene and its homologues each appear to be positioned as the last gene of similar operons that also encode DNA helicase and DNA ligase. E. faecalis has ORFs similar to those coding for DNA helicase and DNA ligase, but lacks a camS homologue at this position. The absence of camS in $E$. faecalis is also indicated by lack of gene-specific polymerase chain reaction (PCR) amplification (see next section). Thus, a 'staph-cAM373-like' activity does not contribute to total pheromone activity in E. faecalis.

The cams homologues are not particularly alike in regions encoding the signal sequences, and the heptapeptides at the carboxyl-terminal ends of the signal sequences are dissimilar. Amino acid sequence comparison of the predicted gene products from $S$. aureus $879 \mathrm{R} 4 \mathrm{~S}$ and $S$. epidermidis RPS2A revealed only $32 \%$ identity in the first $10 \%$ of the preprotein including the signal sequence, compared with $85 \%$ identity in the remaining portion. The seven amino acids just before the cysteine residue in the $S$. epidermidis sequence are ILLLLTA. This peptide was synthesized and tested for its ability to induce clumping of strain FA373; however, no clumping was observed even up to a concentration of $1000 \mathrm{ng} \mathrm{ml}^{-1}$. The comparable heptapeptides of $B$. subtilis 
strain 168 (AVLMLSA) and L. monocytogenes strain 4-b (LTLVLSG) were tested in a similar manner, and neither showed activity up to and including concentrations of $1000 \mathrm{ng} \mathrm{ml}^{-1}$.

\section{On the extent of occurrence of camE and cams in other species}

In addition to $E$. faecalis and $S$. aureus, other bacteria that are known to produce cAM373-like activities include Enterococcus hirae strain 9790 and $S$. gordonii strains Challis and G9B (Clewell et al., 1985). Use of the same primers that amplified a segment of camE from E. faecalis $\mathrm{JH} 2-2$ yielded no product from S. aureus 879R4S, E. hirae 9790 or S. gordonii Challis and G9B; likewise, primers that successfully targeted camS of $S$. aureus 879R4S failed to amplify E. faecalis JH2-2, E. hirae 9790 or S. gordonii Challis and G9B (data not shown). These results indicate that the gene or genes responsible for cAM373-type activity in E. hirae and S. gordonii are not similar enough to either camE or camS to support primer binding and, therefore, a third and possibly fourth unique gene must exist that is capable of producing a peptide to which pAM373 responds.

\section{Discussion}

The genes encoding the production of sex pheromones cAM373 in E. faecalis and staph-cAM373 in S. aureus each specify a seven-amino-acid peptide derived from the carboxyl-terminus of a signal sequence encoded as part of a prelipoprotein. However, the camE and camS determinants appear to be unrelated, with the heptapeptide similarities being only coincidental. No doubt, within enterococcal and other genomes, there exist multiple determinants coding for lipoproteins serving a variety of functions, and peptides processed from their signal sequences may exist to fulfil functions other than, or in addition to, conjugation-related signalling (Dunny et al., 1979; Clewell et al., 1985).

Release of active pheromone molecules requires not only processing of the signal sequence of the prelipoprotein but cleavage at the site that becomes the amino-terminus of the secreted peptide as well. The sex pheromone cAD1 is processed from the signal sequence of a prelipoprotein (An et al., 1999; An and Clewell, 2002) and, in this case, the additional processing is believed to depend on a metalloprotease referred to as Eep, which is a member of a family of proteins that exhibit their activity within membranes (Brown et al., 2000). Eep was found to be unnecessary for processing of cAM373 (An et al., 1999); it is therefore reasonable to assume that an appropriate activity similar to Eep, at least in function, exists in E. faecalis to process cAM373. Indeed, enzymes active in intramembrane proteolysis are widespread throughout nature (Brown et al., 2000).

Mutations of the lipoprotein-encoding portion of camE had no effect on the production of CAM373 in plasmid-free cells, on sensing of cAM373 or on production of the inhibitor peptide iAM373 when an appropriate plasmid was present. Therefore, it does not appear that the CamE lipoprotein is necessary for normal production and secretion of $\mathrm{CAM} 373$ or iAM373, or for feedback regulation of the pheromone system. Thus, the function of mature CamE remains unknown.

The camE gene is situated near, but not transcriptionally linked to, ORFs that appear by homology comparisons to encode $\mathrm{ABC}$ transporter components. Internalization of certain sex pheromones has been shown (Leonard et al., 1996) to depend on an oligopeptide permease $\mathrm{ABC}$ transporter. It is conceivable that the $A B C$ determinants adjacent to camE facilitate the uptake of cAM373 as part of some yet to be identified control circuit.

The camS gene, producing staph-cAM373, appears to be expressed as the last gene of an operon that also includes DNA helicase and DNA ligase. The gene homologues encoding DNA helicase (pcrA) in both $S$. aureus and $B$. subtilis have been reported to be essential (Iordanescu, 1993; Petit et al., 1998); however, the only cams homologue to be published, yerH of Bacillus, is cryptic (Petit et al., 1998).

Differences were found in the signal sequences encoded by cams homologues in $S$. aureus and $S$. epidermidis, revealing that the amino acid sequence required to produce staph-cAM373 is not present in the $S$. epidermidis sequence. This difference may explain the basis of the findings (Clewell et al., 1985; MuschollSilberhorn et al., 1997) that staph-cAM373 pheromone is secreted by most strains of $S$. aureus tested but not by coagulase-negative staphylococci.

The fact that a conjugative E. faecalis plasmid can sense and respond to a peptide signal produced by $S$. aureus suggests the undesirable possibility that such signalling systems could facilitate the acquisition of enterococcal determinants, such as vancomycin resistance genes, by staphylococci. Clinical $S$. aureus strains have been isolated with low-level resistance to vancomycin (Hiramatsu et al., 1997; Smith et al., 1999), in which resistance apparently results from a thickening of the cell wall or associated extracellular material. Thus far, high-level vancomycin resistance caused by a determinant such as enterococcal vanA has not appeared in $S$. aureus but, with the ability to exploit a pheromone-based transfer system, the spread of such determinants would no doubt be enhanced considerably. Indeed, this scenario becomes more plausible in view of a recent report (Showsh et al., 2001) concerning a clinical E. faecalis 
isolate carrying vanA on a conjugative plasmid (pAM368) that, like pAM373, responds to staph-cAM373 produced by $S$. aureus. Although transfer of pAM368 was not attempted, it was demonstrated that pAM373, in the form of a co-integrate with a plasmid able to replicate in $S$. aureus, can transfer conjugatively from $E$. faecalis into $S$. aureus. Transfer of the co-integrate is specifically induced by the pheromone staph-cAM373 (S. E. Flannagan, unpublished observation).

Although Enterococcus is normally considered an inhabitant of the intestinal tract and Staphylococcus is considered to be predominant on the skin, they can be found in close association. Enterococcus and Staphylococcus have been found as co-contaminants on processed poultry (Holder et al., 1997), and staphylococci occur in the intestines of rats (Brunel and Gouet, 1989) and rabbits (Canganella et al., 1992). Vancomycinresistant enterococci may have an opportunity to communicate with staphylococci in the human intestine as well, particularly in the case of infants. Microbial colonization of the human intestine begins shortly after birth with microbiota often derived from the mother's flora (Kirjavainen and Gibson, 1999). As vancomycin-resistant enterococci become more common as colonizers of mothers, these resistant organisms may also become more common in infants. In addition, breast-fed infants continuously ingest staphylococci from maternal skin while nursing. $S$. aureus has been reported (Lindberg et al., 2000) to be a persistent resident of the intestinal tracts of healthy infants and can account for close to $5 \%$ of the facultative isolates in neonatal faecal flora (Rotimi and Duerden, 1981).

Intergeneric exchange between Enterococcus and Staphylococcus probably occurs in nature, and cointegration of enterococcal and staphylococcal plasmids is thought to be involved in the transfer of resistance determinants between these two organisms (Bonafede et al., 1997). A clearer understanding of all the mechanisms involved in intergeneric genetic transfer is needed. One such mechanism, described here, is the ability to produce pheromones such as cAM373 and staphcAM373, which may play a role in the eventual acquisition of high-level vancomycin resistance by $S$. aureus.

\section{Experimental procedures}

\section{Bacterial strains, plasmids and media}

Bacterial strains and plasmids used in this study are listed in Table 3. Todd-Hewitt broth (THB; Difco) was used for the cultivation of E. faecalis, E. hirae, S. aureus and S. gordonii. LB medium ( $1 \%$ tryptone, $0.5 \%$ yeast extract, $0.5 \% \mathrm{NaCl}$ ) was used for the growth of $E$. coli. When needed, the growth medium was solidified by the addition of $1.5 \%$ agar (Fisher). All cultures were incubated at $37^{\circ} \mathrm{C}$. Antibiotics were obtained from Sigma except as noted and used at the following concentrations: rifampicin (Calbiochem), $25 \mu \mathrm{g} \mathrm{ml}^{-1}$; fusidic acid, $25 \mathrm{~g} \mathrm{~m} \mathrm{ml}^{-1}$; streptomycin, $500 \mu \mathrm{g} \mathrm{ml}^{-1}$; tetracycline, $10 \mu \mathrm{g}$ $\mathrm{ml}^{-1}$; erythromycin, $10 \mu \mathrm{g} \mathrm{ml}^{-1}$ for E. faecalis, $200 \mu \mathrm{g} \mathrm{ml}^{-1}$ for E. coli; ampicillin, $50 \mu \mathrm{g} \mathrm{ml}^{-1}$. Common laboratory chemicals and reagents were purchased from Fisher Scientific or Sigma.

\section{DNA manipulation}

For the preparation of genomic DNA, cell lysates using Sarkosyl L-30 (ICN Biochemicals) were prepared essentially as described previously (Clewell et al., 1974) with the following modifications. Cultures were grown aerobically (however, S. gordonii was grown with reduced headspace volume to restrict aeration of the medium) to mid-log phase, at which time glycine was added to a final concentration of $3 \%$. Cells were harvested after one additional hour of growth and incubated at $37^{\circ} \mathrm{C}$ in a final concentration of $1 \mathrm{mg} \mathrm{ml}^{-1}$ lysozyme, $10 \mathrm{U} \mathrm{ml}^{-1}$ mutanolysin and $20 \mu \mathrm{g} \mathrm{ml}^{-1}$ lysostaphin (all from Sigma). Chromosomal DNA was purified by caesium chloride-ethidium bromide gradient centrifugation in a Beckman VC-53 rotor, extracted with saturated isopropanol, dialysed against $1 \mathrm{mM}$ EDTA and recovered by ethanol precipitation using standard protocols (Maniatis et al., 1982).

Plasmid DNA was purified using a Plasmid midi kit (Qiagen) or by a small-scale alkaline lysis method as described previously (Weaver and Clewell, 1988).

Restriction endonucleases (Invitrogen, New England Biolabs, Roche) and DNA ligase (New England Biolabs) were used according to each manufacturer's recommendations. Gels for DNA analysis typically consisted of $0.5 \%$ ultrapure agarose (Invitrogen) plus $0.25 \%$ Synergel (Diversified Biotech) in TAE buffer (Ausubel et al., 1996). For the observation of small fragments, gels were made using $3 \%$ Nusieve GTG agarose (FMC Bioproducts) in TAE buffer. Recovery of DNA fragments from a gel was accomplished using a Qiagen gel extraction kit.

DNA amplification was routinely carried out using AmpliTaq DNA polymerase, PCR core reagents and a 480 thermal cycler (all from PE Biosystems). In some cases, platinum Taq DNA polymerase high fidelity (Invitrogen) was used. PCRs were purified using Qiaquick columns (Qiagen) or by ethanol precipitation.

Transformation of $E$. faecalis and $E$. coli by electroporation was performed as described previously (Flannagan and Clewell, 1991).

\section{DNA sequencing and sequence analysis}

Based on knowledge of the peptide sequence (AIFILAS) of the pheromone cAM373 (Mori et al., 1986), preliminary $E$. faecalis genome sequence data were obtained from AstraZeneca (P. Barth, personal communication; Clewell et al., 2000). A custom primer pair (Ef373-1, Ef373-4) was designed for amplification of genomic DNA from various $E$. faecalis strains. The amplified DNA was then sequenced using primers (Ef373-1-b, Ef373-4-b) with binding sites just within the amplified region.

The peptide sequence (AIFILAA) of the pheromone staphcAM373 is known (Nakayama et al., 1996). Based on pre- 
Table 3. Bacterial strains and plasmids used in this study.

\begin{tabular}{|c|c|c|}
\hline Strain or plasmid ${ }^{a}$ & Description or relevant characteristics ${ }^{b}$ & Reference \\
\hline \multicolumn{3}{|l|}{ Strains } \\
\hline \multicolumn{3}{|l|}{ Enterococcus faecalis } \\
\hline $\mathrm{JH} 2-2$ & $\mathrm{Rf}^{r}, \mathrm{Fa}^{\mathrm{r}}$ & Jacob and Hobbs (1974) \\
\hline OG1X & $\mathrm{Sm}^{r}, \mathrm{Gel}^{-}$ & Ike et al. (1983) \\
\hline DS16 & $\operatorname{Tc}^{r}(\operatorname{Tn} 916)$, carries pAD1 and pAD2 (Tn917, Em) & Tomich et al. (1979) \\
\hline $\mathrm{RC} 73$ & $\mathrm{TC}^{r}$ (Tn918), carries pAM373 and four or more additional plasmids & Clewell et al. (1985) \\
\hline V583 & $\mathrm{Vm}^{r}$, carries three plasmids & Sahm et al. (1989) \\
\hline OG1SS & $\mathrm{Sm}^{r} . \mathrm{Sp}^{r}$ & Franke and Clewell (1981) \\
\hline FA373 & $\mathrm{Rf}^{r}, \mathrm{Fa}^{r}, \mathrm{Tc}^{\mathrm{r}}(\mathrm{Tn} 918)$, carries pAM373 & Clewell et al. (1985) \\
\hline JH2SS & $\mathrm{Sm}^{r}, \mathrm{Sp}^{r}$ & Tomich et al. (1980) \\
\hline $39-5$ & Carries pPD1 and five additional plasmids & Yagi et al. (1983) \\
\hline 5952 & Carries pOB1 and pOB2 & Oliver et al. (1977) \\
\hline SF380 & $\mathrm{Rf}^{r}, \mathrm{Fa}^{r}, \mathrm{Em}^{r}, \mathrm{JH} 2-2$ camE:: & This study \\
\hline SF380R & $\mathrm{Rf}^{r}, \mathrm{Fa}^{\mathrm{r}}, \mathrm{Em}^{\mathrm{s}}$ & This study \\
\hline SF250 & $\mathrm{Rr}^{r}, \mathrm{Fa}^{\mathrm{r}}, \mathrm{Em}^{\mathrm{r}}, \mathrm{JH} 2-2$ camE:: pAM434-250 & This study \\
\hline SF250R & $\mathrm{Rr}^{r}, \mathrm{Fa}^{\mathrm{r}}, \mathrm{Em}^{\mathrm{s}}$ & This study \\
\hline SF13 & $\mathrm{Rf}^{r}, \mathrm{Fa}^{r}, \mathrm{Em}^{\mathrm{r}}, \mathrm{JH} 2-2$ camE::pAM434-13 & This study \\
\hline SF13R & $\mathrm{Rf}^{r}, \mathrm{Fa}^{r}, \mathrm{Em}^{\mathrm{s}}$, greatly reduced level of cAM373 & This study \\
\hline \multicolumn{3}{|l|}{ Enterococcus hirae } \\
\hline 9790 (ATCC) & Carries a cryptic plasmid & Clewell et al. (1985) \\
\hline \multicolumn{3}{|l|}{ Staphylococcus aureus } \\
\hline 879R4S & $\mathrm{Sm}^{r}$, carries a cryptic plasmid & Schaberg et al. (1982) \\
\hline \multicolumn{3}{|l|}{ Streptococcus gordonii } \\
\hline G9B & & Rosan (1976) \\
\hline Challis (NCTC 7868) & & Clewell et al. (1985) \\
\hline \multicolumn{3}{|l|}{ Escherichia coli } \\
\hline $\mathrm{DH} 5 \alpha$ & $\begin{array}{l}\mathrm{F}^{-} \phi 80 \mathrm{~d} / a c \mathrm{Z} \Delta \mathrm{M} 15 \Delta(\text { lacZYA-argF)U169 deoR recA1 endA1 } \\
\text { hsdR17 }\left(\mathrm{r}_{\mathrm{K}}^{-}, \mathrm{m}_{\mathrm{K}}^{+}\right) \text {phoA supE44 } \lambda^{-} \text {thi-1 gyrA96 relA1 }\end{array}$ & Invitrogen \\
\hline \multicolumn{3}{|l|}{ Plasmids } \\
\hline pAM373 & Encodes response to $\mathrm{CAM} 373$ & Clewell et al. (1985) \\
\hline pAM378 & pAM373::Tn918, $\mathrm{Tc}^{r}$ & Clewell et al. (1985) \\
\hline pAD1 & Encodes response to cAD1 & Tomich et al. (1979) \\
\hline pCF10 & Encodes response to cCF10 & Dunny et al. (1982) \\
\hline pPD1 & Encodes response to cPD1 & Yagi et al. (1983) \\
\hline pOB1 & Encodes response to cOB1 & Oliver et al. (1977) \\
\hline pUC19 & E. coli cloning vector, $\mathrm{Ap}^{\mathrm{r}}$ & Invitrogen \\
\hline pAM414 & Full-length camE cloned in pUC19 & This study \\
\hline pAM415 & Truncated camE cloned in pUC19 & This study \\
\hline pAM434 & Suicide vector in E. faecalis, $\mathrm{Em}^{r}, \mathrm{Ap}^{\mathrm{s}}$ & This study \\
\hline pAM434-380 & Internal $380 \mathrm{bp}$ camE fragment of $\mathrm{JH} 2-2$ cloned in pAM434 & This study \\
\hline pAM434-250 & Internal $250 \mathrm{bp}$ camE fragment of $\mathrm{JH} 2-2$ cloned in pAM434 & This study \\
\hline pAM434-13 & camE containing frameshift cloned in pAM434 & This study \\
\hline pVA749 & $\mathrm{Em}^{\mathrm{r}}$ & Macrina et al. (1982) \\
\hline pBluescript-II KS+ & E. coli cloning vector, $\mathrm{Ap}^{\mathrm{r}}$ & Stratagene \\
\hline pAM435 & pBluescript-II KS+ containing Notl, Ascl, Fsel sites & This study \\
\hline pAM432 & Intermediate in construction of pAM434 & This study \\
\hline pAM433 & Intermediate in construction of pAM434 & This study \\
\hline
\end{tabular}

a. Enterococcus faecalis was formerly Streptococcus faecalis; Enterococcus hirae 9790 was formerly Enterococcus faecium 9790; Streptococcus gordonii G9B and Challis were formerly Streptococcus sanguis. ATCC, American Type Culture Collection; NCTC, National Collection of Type Cultures.

b. Rf, rifampicin; Fa, fusidic acid; Sm, streptomycin; Em, erythromycin; Tc, tetracycline; Sp, spectinomycin; Vm, vancomycin; Ap, ampicillin; Gel, gelatinase.

liminary data (P. Barth, personal communication), custom primers were designed and used to amplify and sequence the appropriate region from the genome of $S$. aureus 879R4S.

DNA sequencing was performed at the University of Michigan DNA sequencing core facility using purified plasmid or PCR templates. DNA sequence data and deduced protein products were analysed using MACVECTOR 6.0 software (Oxford Molecular Group).
Comparative sequence information was acquired from the GenBank database of the National Center for Biotechnology Information (NCBI; http://www.ncbi.nlm.nih.gov) and from the unfinished genome database of The Institute for Genomic Research (TIGR; http://www.tigr.org).

\section{Oligonucleotide primers}

The custom oligonucleotides and primers used for vector @ 2002 Blackwell Science Ltd, Molecular Microbiology, 44, 803-817 
construction, PCR amplification, DNA sequencing and RNA primer extension analyses were obtained from the University of Michigan DNA synthesis core facility or from Invitrogen. Not all primers are listed; however, those of greater significance to the results of the study are as follows. Ef373-1, 5'-ATCGAATTCACGGGATTATTTTGATTGTAATTAG-3'; Ef373-1-b, 5'-CCTGCCCGAATGGCAGCGAAA-5', Ef373-2, 5'-ATCGAATTCAGATGCTGTCACTGATACTAAGTAC-3'; Ef373-3, 5'-ACTGAATTCTTTTAACATCTACTGTATAAACAA G-3'; Ef373-4, 5'-ACTGAATTCTTACTTAAAAGAATGAAAT TGGGAC-3'; Ef373-4-b, 5'-TAGGTTCTGTCCCAAAGAGTA3'; Ef373-5, 5'-ACTGAATTCAACTAGCTAAAATAAAAATAG CTCC-5'; Ef373-6, 5'-ATCGAATTCTGAAATCTATGAAAAA GAAGCTGGC-3'; Ef373-7, 5'-ACTGAATTCTTCTTTTTTT GCTTTGGCTAAAACG-3'; Ef373-8, 5'-GCCACAACTAGCT AAAATAAAAATAGCTCC-3'.

\section{Strain construction}

pAM414 was constructed using high-fidelity DNA polymerase with primers Ef373-1 and Ef373-4 to amplify camE from JH22 on a $0.9 \mathrm{~kb}$ fragment, which was then ligated to pUC19 at the unique EcoRI site and used for transformation of $\mathrm{DH} 5 \alpha$. Primers Ef373-1 and Ef373-5 were used to amplify a short segment of $\mathrm{JH} 2-2$ containing the camE promoter region and $5^{\prime}$ end of the gene. After ligation to pUC19 at the EcoRI site and transformation of $\mathrm{DH} 5 \alpha$, an isolate was selected containing a plasmid designated pAM415. Aside from the engineered translation stop codon specified by Ef373-5, the cloned portion is free from mutations.

DNA segments of $380 \mathrm{bp}$ (using primers Ef373-2 and Ef373-3) or $250 \mathrm{bp}$ (using primers Ef373-6 and Ef373-7) of the internal portion of the $\mathrm{JH} 2-2$ camE gene were generated by PCR and individually cloned into pAM434 at its unique EcoRI site, producing pAM434-380 and pAM434-250 respectively. These plasmids, which are unable to replicate in $E$. faecalis, were introduced into $\mathrm{JH} 2-2$ by electroporation producing strains SF380 and SF250 respectively. Expression of erythromycin resistance from the vector was used to select for integration of each construct into the chromosome. A revertant of each mutant was chosen (designated SF380R and SF250R) by screening for erythromycin-sensitive isolates after excision of the vector during serial passage growth in the absence of antibiotic.

A full-length clone of the camE gene from JH2-2, with a random point deletion, was fortuitously generated by PCR using primers Ef373-1 and Ef373-4. The deletion of an adenine residue, from within the run of seven soon after the start codon of camE, resulted in a frameshift and the appearance of a translation stop codon (TAG) situated just upstream (with $2 \mathrm{bp}$ intervening) of the pheromone-encoding segment. From the pUC19-based clone in which it was identified, the frameshifted gene was subcloned into the suicide vector pAM434 at its unique EcoRI site. The integrity of the subcloned insert was verified by sequencing, and the new construct, termed pAM434-13, was used to transform E. faecalis $\mathrm{JH} 2-2$. An erythromycin-resistant transformant, SF13, was then grown by serial passage in the absence of antibiotic with periodic screening for erythromycin sensitivity. Over the course of 26 days, a total of 13 erythromycin-sensitive isolates were obtained. Eight of these produced CAM373 activ- ity at normal levels, but five (from the same plating) produced activity at a greatly reduced level. Three of the five, along with SF13, were analysed by sequencing of a PCR-amplified fragment encompassing the promoter region and the entire camE ORF. As expected, a mixed sequence showed the presence of two alleles in SF13, but the erythromycinsensitive isolates exhibited only the sequence containing the frameshift, verifying gene replacement by allelic exchange. No other alteration in the gene was present. One of these isolates, designated SF13R, was chosen for further analysis.

To evaluate effects on plasmid-related functions, pAM378, a pAM373 derivative with tetracycline resistance, was used as a selectable marker. The plasmid was conjugatively transferred to each appropriate strain from donor JH2SS/pAM378 with selection on rifampicin, fusidic acid and tetracycline, followed by verification of the plasmid by agarose gel electrophoresis (data not shown).

\section{Construction of suicide vector pAM434}

Plasmid pAM434 (Fig. 6) was created as a vehicle to introduce cloned gene portions into the $E$. faecalis chromosome in order to interrupt the camE gene. A small, ampicillinsensitive vector with several cloning sites and a marker selectable in both $E$. coli and $E$. faecalis was desired to facilitate cloning and integration without the possibility of introducing a $\beta$-lactamase-producing component into the $E$. faecalis background. pAM434 is a small (3410 bp) ampicillinsensitive, erythromycin-resistant suicide vector with multiple

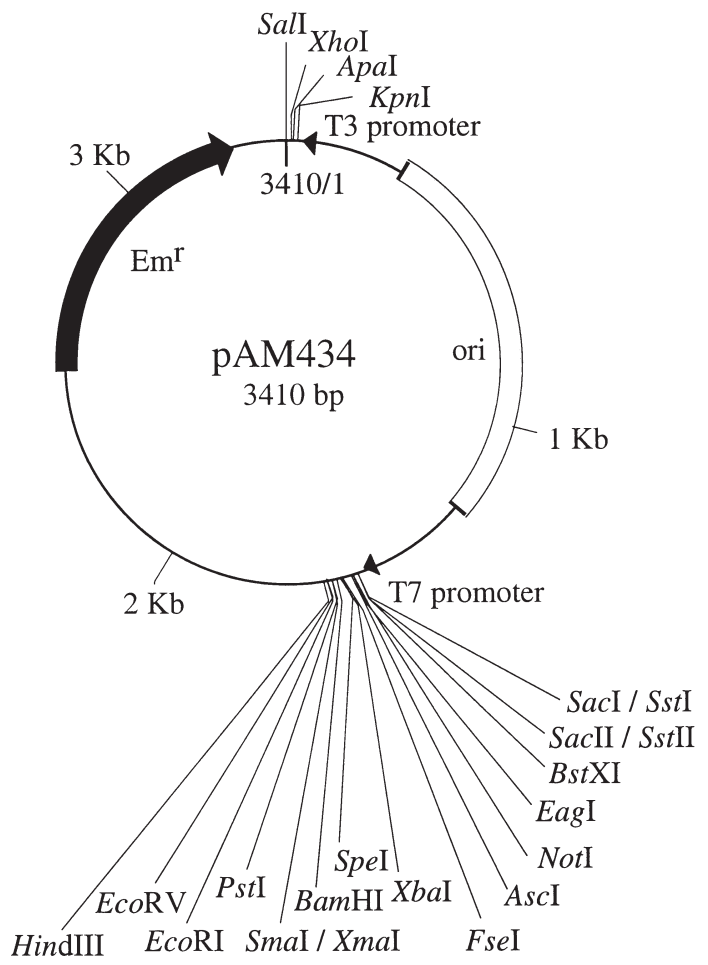

Fig. 6. Suicide vector pAM434. All restriction sites shown are unique. Base \#1 is defined as the first guanine residue in the Sall site (GTCGAC). The pAM434 sequence is available under GenBank accession number AF435436. 
unique cloning sites, including sites that occur rarely in $E$. faecalis to facilitate cloning of gene portions or entire genes by PCR amplification. It replicates at high copy number in E. coli [growing on $200 \mu \mathrm{g} \mathrm{ml}^{-1} \mathrm{Em}$; minimum inhibitory concentration $(\mathrm{MIC})>5000 \mu \mathrm{g} \mathrm{ml}^{-1}$ ], but does not replicate in E. faecalis. It contains the Col $\mathbb{E}_{1}$ origin of replication from the Stratagene vector pBluescript-II $\mathrm{KS}+$ and the erm gene from pVA749 (Macrina et al., 1982) (originally from pAM $\beta 1$; Clewell et al., 1974). It can be integrated into the E. faecalis chromosome by homologous recombination with a cloned segment, where it expresses erythromycin resistance (integrants selected on $10 \mu \mathrm{g} \mathrm{ml}^{-1} \mathrm{Em}$; MIC $>3000 \mu \mathrm{g} \mathrm{ml}^{-1}$ ).

pAM434 was constructed as follows. A cassette of rarely occurring sites (Notl, Ascl and Fsel), bordered by Xbal sites, was made from complimentary oligomers and inserted into pBluescript-II KS+ at the Xbal site, creating pAM435. pAM435 was digested with BsrDI and Pvul, and the largest resulting fragment was ligated to itself. The $P v u l$ site (atbp 500 on the pBluescript-II map, GenBank accession no. X52328) and the BsrDI site (at bp 2107 on pBluescript-II) are compatible and were ligated together. This removed ampicillin resistance because only $132 \mathrm{bp}(15 \%)$ of the distal portion of bla remains. This construct was a replicon, but had no selectable marker; it existed only transiently during the construction of pAM432. The replicon was opened with Hindlll at its unique site, and pVA749 was cut at its unique HindIII site; the two were ligated together, resulting in pAM432. pAM433 was derived from pAM432 by cutting with Notl and ligating. This combined two Notl sites into one and removed an intervening $X b a l$ site, resulting in a plasmid with unique Notl and Xbal sites. pAM434 was derived from pAM433 by digesting with Clal and ligating the largest fragment to itself. This removed the Gram-positive origin of replication. (Note that pAM434 cannot be cut with Clal because of imprecise regeneration of the recognition sequence at the ligation site.) pAM434 was sequenced in its entirety on both strands.

\section{Hybridization analyses}

Southern blotting of gels onto supported nitrocellulose membranes (Schleicher and Schuell BAS-NC, $0.2 \mu \mathrm{m}$ ) was carried out by standard procedures (Maniatis et al., 1982). Radiolabelled DNA probes and molecular weight markers were prepared using a nick translation kit from Invitrogen and $[\alpha-$ $\left.{ }^{32} \mathrm{P}\right]$-dATP from Amersham. Hybridization using standard protocols (Maniatis et al., 1982) was carried out at $65^{\circ} \mathrm{C}$ and made use of a Hybaid mini oven MK II, followed by exposure to Kodak X-OMAT film. Screening of multiple isolates was accomplished by lifting colonies onto a supported nitrocellulose membrane (Schleicher and Schuell Optitran, $0.45 \mu \mathrm{m}$ ), followed by lysing of the cells and fixing of the DNA onto the membrane by standard protocols (Ausubel et al., 1996), and hybridization with a radiolabelled probe as above.

\section{Microtitre assays}

Production of pheromone activity, production of inhibitor activity and response to pheromone were tested using microtitre twofold dilution assays as described previously
(Dunny et al., 1979; Ike et al., 1983) with some modifications as follows. Todd-Hewitt medium was used in all tests involving growth or response of $E$. faecalis, and LB medium was used for growth of $E$. coli. To prepare culture supernatant for testing of pheromone or inhibitor activity, $5 \mathrm{ml}$ cultures with a 1:100 inoculum were grown to very early stationary phase, pelleted, and the supernatant was passed through a Millipore $0.22 \mu \mathrm{m}$ membrane filter and heated in a boiling water bath for $15 \mathrm{~min}$. FA373 (a 10-fold dilution in fresh broth of an overnight culture) was used as the responder strain unless otherwise noted. Synthetic peptides were obtained from the University of Michigan protein core synthesis facility, Peninsula Laboratories or PeptidoGenic Research.

\section{Primer extension analyses}

Total RNA was prepared as described previously (Bastos et al., 1998) except that the cultures were grown at $37^{\circ} \mathrm{C}$. Primer end-labelling with $\left[\gamma_{-}{ }^{32} \mathrm{P}\right]$-ATP (Amersham) and DNA sequencing (for primer extension comparisons) were carried out using an fmol sequencing system kit from Promega. Extension of RNA transcripts was performed using a Superscript first-strand synthesis system for reverse transcriptase (RT)-PCR from Invitrogen. Extended products were analysed by denaturing PAGE using 7.5\% acrylamide (Roche), 7.5 M urea (Fisher) and 0.5× TBE buffer (Maniatis et al., 1982) followed by exposure to Kodak X-OMAT film.

\section{Accession numbers}

GenBank accession numbers for submitted sequences are as follows: pAM434, AF435436; camE gene of JH2-2, AF435437; camE gene of OG1X, AF435439; camE gene of DS16, AF435440; camE gene of RC73, AF435441; camE gene of V583, AF435442; camS gene of 879R4S, AF435443.

\section{Acknowledgements}

The authors thank their laboratory colleagues F. An, E. De Boever, M. V. Francia, A. Hammerum, S. Showsh and H. Tomita, for helpful comments and discussions. P. Barth is gratefully acknowledged for providing preliminary sequence data. This work was supported by National Institutes of Health grant GM33956. Preliminary sequence data were obtained from The Institute for Genomic Research (TIGR) website at http://www.tigr.org. TIGR sequencing of $E$. faecalis and $S$. epidermidis was accomplished with support from the National Institute of Allergy and Infectious Diseases; sequencing of $S$. aureus was accomplished with support from the National Institute of Allergy and Infectious Diseases and the Merck Genome Research Institute; sequencing of L. monocytogenes was accomplished with support from the United States Department of Agriculture.

\section{References}

An, F.Y., and Clewell, D.B. (2002) Identification of the cAD1 sex pheromone precursor in Enterococcus faecalis. $J$ Bacteriol 184: 1880-1887. 
An, F.Y., Sulavik, M.C., and Clewell, D.B. (1999) Identification and characterization of a determinant (eep) on the Enterococcus faecalis chromosome that is involved in production of the peptide sex pheromone cAD1. J Bacteriol 181: $5915-5921$.

Arthur, M., and Courvalin, P. (1993) Genetics and mechanisms of glycopeptide resistance in enterococci. Antimicrob Agents Chemother 37: 1563-1571.

Ausubel, F.M., Brent, R., Kingston, R.E., Moore, D.D., Seidman, J.G., Smith, J.A., and Struhl, K. (eds) (1996) Current Protocols in Molecular Biology. New York: John Wiley \& Sons.

Bastos, M.C.F., Tomita, H., Tanimoto, K., and Clewell, D.B. (1998) Regulation of the Enterococcus faecalis pAD1related sex pheromone response: analyses of traD expression and its role in controlling conjugation functions. $\mathrm{Mol}$ Microbiol 30: 381-392.

Bonafede, M.E., Carias, L.L., and Rice, L.B. (1997) Enterococcal transposon Tn5384: evolution of a composite transposon through cointegration of enterococcal and staphylococcal plasmids. Antimicrob Agents Chemother 41: 1854-1858.

Brown, M.S., Ye, J., Rawson, R.B., and Goldstein, J.L. (2000) Regulated intramembrane proteolysis: a control mechanism conserved from bacteria to humans. Cell 100: 391-398.

Brunel, A., and Gouet, P. (1989) Intestinal microflora of the newborn rat as related to mammary, faecal, and vaginal Staphylococci strains isolated from the dam. Can $J$ Microbiol 35: 989-993.

Canganella, F., Zirletta, G., Gualterio, L., Massa, S., and Trovatelli, L.D. (1992) Anaerobic facultative bacteria isolated from the gut of rabbits fed different diets. Zentralbl Mikrobiol 147: 537-540.

Clark, N.C., Cooksey, R.C., Hill, B.C., Swenson, J.M., and Tenover, F.C. (1993) Characterization of glycopeptideresistant enterococci from US hospitals. Antimicrob Agents Chemother 37: 2311-2317.

Clewell, D.B. (1981) Plasmids, drug resistance, and gene transfer in the genus Streptococcus. Microbiol Rev 45: 409-436.

Clewell, D.B. (1990) Movable genetic elements and antibiotic resistance in enterococci. Eur J Clin Microbiol Infect Dis 9: 90-102.

Clewell, D.B. (1993) Bacterial sex pheromone-induced plasmid transfer. Cell 73: 9-12.

Clewell, D.B. (1999) Sex pheromone systems in enterococci. In Cell-Cell Signaling in Bacteria. Dunny, G.M., and Winans, S.C. (eds). Washington, DC: American Society for Microbiology Press, pp. 47-65.

Clewell, D.B., and Brown, B.L. (1980) Sex pheromone cAD1 in Streptococcus faecalis: induction of a function related to plasmid transfer. J Bacteriol 143: 1063-1065.

Clewell, D.B., Yagi, Y., Dunny, G.M., and Schultz, S.K. (1974) Characterization of three plasmid deoxyribonucleic acid molecules in a strain of Streptococcus faecalis: identification of a plasmid determining erythromycin resistance. $J$ Bacteriol 117: 283-289.

Clewell, D.B., An, F.Y., White, B.A., and Gawron-Burke, C. (1985) Streptococcus faecalis sex pheromone (cAM373) also produced by Staphylococcus aureus and identification of a conjugative transposon (Tn918). J Bacteriol 162: 1212-1220.

Clewell, D.B., An, F.Y., Flannagan, S.E., Antiporta, M., and Dunny, G.M. (2000) Enterococcal sex pheromone precursors are part of signal sequences for surface lipoproteins. Mol Microbiol 35: 246-247.

De Boever, E.H., and Clewell, D.B. (2001) The Enterococcus faecalis pheromone-responsive plasmid pAM373 does not encode an entry exclusion function. Plasmid 45: 57-60.

De Boever, E.H., Clewell, D.B., and Fraser, C.M. (2000) Enterococcus faecalis conjugative plasmid pAM373: complete nucleotide sequence and genetic analyses of sex pheromone response. Mol Microbiol 37: 1327-1341.

Dunny, G.M., and Leonard, B.A.B. (1997) Cell-cell communication in gram-positive bacteria. Annu Rev Microbiol 51: 527-564.

Dunny, G.M., Brown, B.L., and Clewell, D.B. (1978) Induced cell aggregation and mating in Streptococcus faecalis: Evidence for a bacterial sex pheromone. Proc Natl Acad Sci USA 75: 3479-3483.

Dunny, G.M., Craig, R.A., Carron, R.L., and Clewell, D.B. (1979) Plasmid transfer in Streptococcus faecalis. Production of multiple sex pheromones by recipients. Plasmid 2: 454-465.

Dunny, G., Yuhasz, M., and Ehrenfeld, E. (1982) Genetic and physiological analysis of conjugation in Streptococcus faecalis. J Bacteriol 151: 855-859.

Eaton. T.J., and Gasson, M.J. (2001) Molecular screening of Enterococcus virulence determinants and potential for genetic exchange between food and medical isolates. Appl Environ Microbiol 67: 1628-1635.

Flannagan, S.E., and Clewell, D.B. (1991) Conjugative transfer of Tn916. Enterococcus faecalis: trans activation of homologous transposons. J Bacteriol 173: 71367141.

Franke, A.E., and Clewell, D.B. (1981) Evidence for a chromosome-borne resistance transposon (Tn916) in Streptococcus faecalis that is capable of 'conjugal' transfer in the absence of a conjugative plasmid. J Bacteriol 145: 494-502.

Gilmore, M.S., Segarra, R.A., Booth, M.C., Bogie, C.P., Hall, L.R., and Clewell, D.B. (1994) Genetic structure of the Enterococcus faecalis plasmid pAD1-encoded cytolytic toxin system and its relationship to lantibiotic determinants. $J$ Bacteriol 176: 7335-7344.

Halling, S.M., and Kleckner, N. (1982) A symmetrical sixbase-pair target site sequence determines Tn10 insertion specificity. Cell 28: 155-163.

Hiramatsu, K., Hanaki, H., Ino, T., Yabuta, K., Oguri, T., and Tenover, F.C. (1997) Methicillin-resistant Staphylococcus aureus clinical strain with reduced vancomycin susceptibility. J Antimicrob Chemother 40: 135-146.

Hirt, H., Erlandsen, S.L., and Dunny, G.M. (2000) Heterologous inducible expression of Enterococcus faecalis pCF10 aggregation substance Asc10 in Lactococcus lactis and Streptococcus gordonii contributes to cell hydrophobicity and adhesion to fibrin. J Bacteriol 182: 2299-2306.

Holder, J.S., Corry, J.E.L., and Hinton, M.H. (1997) Microbial status of chicken portions and portioning equipment. $\mathrm{Br}$ Poult Sci 38: 505-511.

Huycke, M.M., Sahm, D.F., and Gilmore, M.S. (1998) 
Multiple-drug resistant enterococci. the nature of the problem and an agenda for the future. Emerg Infect Dis 4: 239-249.

Ike, Y., Craig, R.A., White, B.A., Yagi, Y., and Clewell, D.B. (1983) Modification of Streptococcus faecalis sex pheromones after acquisition of plasmid DNA. Proc Natl Acad Sci USA 80: 5369-5373.

Iordanescu, S. (1993) Characterization of the Staphylococcus aureus chromosomal gene pcrA, identified by mutations affecting plasmid pT181 replication. Mol Gen Genet 241: 185-192.

Jacob, A.E., and Hobbs, S.J. (1974) Conjugal transfer of plasmid-borne multiple antibiotic resistance in Streptococcus faecalis var. zymogenes. J Bacteriol 117: 360-372.

Kirjavainen, P.K., and Gibson, G.R. (1999) Healthy gut microflora and allergy: factors influencing development of the microbiota. Ann Med 31: 288-292.

Leonard, B.A.B., Podbielski, A., Hedberg, P.J., and Dunny, G.M. (1996) Enterococcus faecalis pheromone binding protein, PrgZ, recruits a chromosomal oligopeptide permease system to import sex pheromone cCF10 for induction of conjugation. Proc Natl Acad Sci USA 93: 260-264.

Lindberg, E., Nowrouzian, F., Adlerberth, I., and Wold, A.E. (2000) Long-time persistence of superantigen-producing Staphylococcus aureus strains in the intestinal microflora of healthy infants. Pediatr Res 48: 741-747.

Macrina, F.L., Tobian, J.A., Jones, K.R., and Evans, R.P. (1982) Molecular cloning in the Streptococci. In Genetic Engineering of Microorganisms for Chemicals. Hollaender, A., Demoss, R.D., Kaplan, S., Konisky, J., Savage, D., and Wolfe, R.S. (eds). New York: Plenum Press, pp. 195210.

Maniatis, T., Fritsch, E.F., and Sambrook, J. (1982) Molecular Cloning: a Laboratory Manual. Cold Spring Harbor, NY: Cold Spring Harbor Laboratory Press.

Mori, M., Tanaka, H., Sakagami, Y., Isogai, A., Fujino, M., Kitada, C., et al. (1986) Isolation and structure of the Streptococcus faecalis sex pheromone, cAM373. FEBS Lett 206: 69-72.

Murray, B.E. (1998) Diversity among multidrug-resistant enterococci. Emerg Infect Dis 4: 37-47.

Muscholl-Silberhorn, A., Samberger, E., and Wirth, R. (1997) Why does Staphylococcus aureus secrete an Enterococcus faecalis-specific pheromone? FEMS Microbiol Lett 157: $261-266$.

Nagarajan, V. (1993) Protein secretion. In Bacillus subtilis and other Gram-Positive Bacteria. Sonenshein, A.L., Hoch, J.A., and Losick, R. (eds). Washington, DC: American Society for Microbiology Press, pp. 713-726.

Nakayama, J., Ono, Y., and Suzuki, A. (1995) Isolation and structure of the sex pheromone inhibitor, iAM373, of Enterococcus faecalis. Biosci Biotech Biochem 59: 13581359.

Nakayama, J., Igarashi, S., Nagasawa, H., Clewell, D.B., An, F.Y., and Suzuki, A. (1996) Isolation and structure of staphcAM373 produced by Staphylococcus aureus that induces conjugal transfer of Enterococcus faecalis plasmid pAM373. Biosci Biotech Biochem 60: 1038-1039.

Oliver, D.R., Brown, B.L., and Clewell, D.B. (1977) Characterization of plasmids determining hemolysin and bac- teriocin production in Streptococcus faecalis 5952. J Bacteriol 130: 948-950.

Petit, M.A., Dervyn, E., Rose, M., Entian, K.D., McGovern, S., Ehrlich, S.D., and Bruand, C. (1998) PcrA is an essential DNA helicase of Bacillus subtilis fulfilling functions both in repair and rolling-circle replication. Mol Microbiol 29: 261-273.

Rosan, B. (1976) Relationship of the cell wall composition of group $\mathrm{H}$ streptococci and Streptococcus sanguis to their serological properties. Infect Immun 13: 1144-1153.

Rotimi, V.O., and Duerden, B.I. (1981) The development of the bacterial flora in normal neonates. J Med Microbiol 14: 51-62.

Rozdzinski, E., Marre, R., Susa, M., Wirth, R., and MuschollSilberhorn, A. (2001) Aggregation substance-mediated adherence of Enterococcus faecalis to immobilized extracellular matrix proteins. Microb Pathol 30: 211-220.

Sahm, D.F., Kissinger, J., Gilmore, M.S., Murray, P.R., Mulder, R., Solliday, J., and Clarke, B. (1989) In vitro susceptibility studies of vancomycin-resistant Enterococcus faecalis. Antimicrob Agents Chemother 33: 1588-1591.

Schaberg, D.R., Clewell, D.B., and Glatzer, L. (1982) Conjugative transfer of R-plasmids from Streptococcus faecalis to Staphylococcus aureus. Antimicrob Agents Chemother 22: 204-207.

Schwan, W.R., Coulter, S.N., Ng, E.Y.W., Langhorne, M.H., Ritchie, H.D., Brody, L.L., et al. (1998) Identification and characterization of the PutP proline permease that contributes to in vivo survival of Staphylococcus aureus in animal models. Infect Immun 66: 567-572.

Showsh, S.A., De Boever, E.H., and Clewell, D.B. (2001) Vancomycin resistance plasmid in Enterococcus faecalis that encodes sensitivity to a sex pheromone also produced by Staphylococcus aureus. Antimicrob Agents Chemother 45: 2177-2178.

Singleton, P., and Sainsbury, D. (1996) Dictionary of Microbiology and Molecular Biology, 2nd edn. Chichester: John Wiley \& Sons.

Smith, T.L., Pearson, M.L., Wilcox, K.R., Cruz, C., Lancaster, M.V., Robinson-Dunn, B., et al. (1999) Emergence of vancomycin resistance in Staphylococcus aureus. $N$ Engl $J$ Med 340: 493-501.

Tomich, P.K., An, F.Y., Damle, S.P., and Clewell, D.B. (1979) Plasmid-related transmissibility and multiple drug resistance in Streptococcus faecalis subsp. zymogenes strain DS16. Antimicrob Agents Chemother 15: 828-830.

Tomich, P.K., An, F.Y., and Clewell, D.B. (1980) Properties of erythromycin-inducible transposon Tn917. Streptococcus faecalis. J Bacteriol 141: 1366-1374.

Weaver, K.E., and Clewell, D.B. (1988) Regulation of the pAD1 sex pheromone response in Enterococcus faecalis: construction and characterization of lac $Z$ transcriptional fusions in a key control region of the plasmid. J Bacteriol 170: 4343-4352.

Wengender, P.A., and Miller, K.J. (1995) Identification of a PutP proline permease gene homolog from Staphylococcus aureus by expression cloning of the high-affinity proline transport system in Escherichia coli. Appl Environ Microbiol 61: 252-259.

Wirth, R. (1994) The sex pheromone system of Enterococ- 
Sex pheromone genes in E. faecalis and S. aureus 817

cus faecalis More than just a plasmid-collection mechanism? Eur J Biochem 222: 235-246.

Wu, H.C. (1996) Biosynthesis of lipoproteins. In Escherichia coli and Salmonella: Cellular and Molecular Biology. Neidhardt, F.C., Curtiss, R., Ingraham, J.L., Lin, E.C.C., Low, K.B., Magasanik, B., et al. (eds). Washington,
DC: American Society for Microbiology Press, pp. 1005-1014.

Yagi, Y., Kessler, R.E., Shaw, J.H., Lopatin, D.E., An, F., and Clewell, D.B. (1983) Plasmid content of Streptococcus faecalis strain 39-5 and identification of a pheromone (cPD1)induced surface antigen. J Gen Microbiol 129: 1207-1215. 